\title{
Plasma IL-8 concentrations are increased in dogs with spirocercosis
}

Dvir, E.; Mellanby, R. J.; Kjelgaard-Hansen, Mads; Schoeman, J. P.

Published in:

Veterinary Parasitology

DOI:

10.1016/j.vetpar.2012.06.007

Publication date:

2012

Document version

Early version, also known as pre-print

Citation for published version (APA):

Dvir, E., Mellanby, R. J., Kjelgaard-Hansen, M., \& Schoeman, J. P. (2012). Plasma IL-8 concentrations are increased in dogs with spirocercosis. Veterinary Parasitology, 190(1-2), 185-190.

https://doi.org/10.1016/j.vetpar.2012.06.007 


\title{
Plasma IL-8 concentrations are increased in dogs with spirocercosis
}

\author{
E. Dvir ${ }^{\mathrm{a}, *}$, R.J. Mellanby ${ }^{\text {, }}$, M. Kjelgaard-Hansen ${ }^{\mathrm{c}}$, J.P. Schoeman ${ }^{\mathrm{a}}$ \\ a Department of Companion Animal Clinical Studies, Faculty of Veterinary Science, University of Pretoria, South Africa \\ b Royal (Dick) School of Veterinary Studies, Roslin Institute, Division of Veterinary Clinical Studies, University of Edinburgh, Midlothian, UK \\ c Department of Small Animal Clinical Sciences, Faculty of Life Sciences, University of Copenhagen, Denmark
}

\section{A R T I C L E I N F O}

\section{Article history:}

Received 7 February 2012

Received in revised form 8 June 2012

Accepted 10 June 2012

\section{Keywords:}

Spirocercosis

Spirocerca lupi

Cytokines

Interleukin 8

Interleukin 18

Sarcoma

\begin{abstract}
A B S T R A C T
The nematode Spirocerca lupi ( $\mathrm{S}$. lupi) induces sarcoma in the dog oesophagus in about $25 \%$ of cases. The aim of this study was to compare the differences in the cytokine milieu between dogs with neoplastic $(n=29)$ and non-neoplastic disease $(n=49)$ and age- and gender-matched healthy controls $(n=25)$. We measured IL-2, IL-4, IL-6, IL-8, IL-10, IL-18, GM-CSF and MCP-1 in a specific canine multiplex immunoassay kit. Cytokine concentrations were compared between the different groups using the Kruskal-Wallis test followed by Dunn's test.

Only IL-8 and IL-18 showed significant differences in their plasma concentration among the three groups. Kruskal-Wallis test revealed a significant $(p=0.001)$ difference in IL- 8 concentration between the neoplastic group $(634 \mathrm{pg} / \mathrm{ml})$, the non-neoplastic $(429 \mathrm{pg} / \mathrm{ml})$ and the control groups $(150 \mathrm{pg} / \mathrm{ml})$. Post-test analysis revealed a significance difference between the two $S$. lupi groups and the control group $(p<0.01)$. The highest IL-18 concentration was found in the non-neoplastic group $(53 \mathrm{pg} / \mathrm{ml})$, followed by the control group $(46 \mathrm{pg} / \mathrm{ml})$ and finally the neoplastic group ( $33 \mathrm{pg} / \mathrm{ml})$. IL-18 concentrations were significantly higher in the non-neoplastic group than in the neoplastic group $(p=0.05)$.

The increased IL- 8 in the spirocercosis groups is consistent with the neutrophilic infiltrate in spirocercosis lesions and in those of other inflammatory-induced neoplasias such as Barret's oesophagus and Helicobacter gastritis. IL-18 showed negative regulatory effect in several worm infections and it is possible that it plays the same role in spirocercosis, allowing the worm to evade the host response and to induce neoplastic transformation.
\end{abstract}

(c) 2012 Elsevier B.V. All rights reserved.

\section{Introduction}

Spirocercosis is a disease caused by the Spirocerca lupi (S. lupi) nematode in dogs (Bailey, 1972). The disease occurs worldwide throughout tropical and subtropical areas, in very high prevalence in certain locations (Dvir et al., 2001).

\footnotetext{
* Corresponding author at: Diplomate of the European College of Veterinary Internal Medicine-Companion Animals (Dipl. ECVIM-CA), Section of Small Animal Medicine, Department of Companion Animal Clinical Studies, Faculty of Veterinary Science, University of Pretoria, Private Bag X04, Onderstepoort 0110, South Africa. Tel.: +27 12529 8366; fax: +27 125298308 .

E-mail addresses: eran.dvir@up.ac.za, edvir2000@yahoo.com (E. Dvir).
}

In South Africa the prevalence in some areas may reach up to $70 \%$ (Kok et al., 2010). At the end of the migration route within the dog the adult worm settles in a fibro-inflammatory nodule in the caudal oesophagus (Dvir et al., 2010). These nodules transform to a sarcoma in approximately 25\% of cases (Dvir et al., 2001). The initial non-neoplastic nodule shows marked inflammation that involve myeloid cells (predominantly neutrophils) and lymphoplasmacytic cells (with high prevalence of CD3+ T cells and to a lesser degree Pax5+ B cells) (Dvir et al., 2011). There is also evidence of an increased systemic inflammatory response in both the neoplastic and non-neoplastic stages that is reflected as a leukocytosis (Dvir et al., 2008) and an elevated C-reactive protein (CRP) (Mukorera et al., 2011). 
The association between chronic infection-induced inflammation and cancer is now well-described and is thought to be the mechanism responsible for up to $18 \%$ of cancers globally (Vennervald and Polman, 2009). In terms of parasite-associated malignancies, three helminth infections have been classified as carcinogenic in humans, namely Schistosoma haematobium, Clonorchis sinensis and Opisthorchis viverrini (Vennervald and Polman, 2009), while Schistosoma mansoni (S. mansoni) is suspected to be carcinogenic (Yoshida et al., 2002). In dogs, oesophageal sarcoma (excluding leiomyosarcoma) is almost invariably associated with S. lupi infections, whereas in human oncogenic helminth-associated neoplasia the association is limited to only a portion of the specific cancer cases (Herrera et al., 2005), making spirocercosis a highly attractive model to study the association between cancer, helminth infection and inflammation.

Our central hypothesis, while investigating the neoplastic transformation and the inflammatory response in canine spirocercosis, was that the parasite produces excretory product(s) which diverts the immune response from a $\mathrm{T}$ helper 1 (Th1) to Th2 cell response, typical of many nematode infections, and further to an immunoregulatory (immunosuppressive), FoxP3+ regulatory $\mathrm{T}$ cell-predominated response which then facilitates neoplastic transformation. This immune response is welldescribed across species. It is associated with fibroblastic proliferation and has been classified as a delayed hypersensitivity type 3 (Meeusen, 1999). The potential link between switching from Th1 to Th2 response and cancer formation was demonstrated in $S$. mansoni-infected mice that were injected with fibrosarcoma cells. The infected mice had upregulation of their Th2 responses and consequently had a significantly weaker rejection of the cancer cells compared to the non-infected mice that showed Th1 response and stronger rejection (Yoshida et al., 2002). Increased numbers and proportions of Foxp3+ Tregs within tumours are well described in humans (Carreras et al., 2006; Unitt et al., 2005; Xue et al., 2009) and murine models (Imai et al., 2007), including models of fibrosarcoma (Betts et al., 2007). Surprisingly, Foxp3+ cells are rarely observed in $S$. lupi-associated oesophageal nodules and when present, are usually in very small numbers (Dvir et al., 2011). However, they are found in large numbers within CD3+ regions of the bronchial lymph nodes that are draining these lesions (Dvir et al., 2011). These findings cannot completely exclude the possibility of Treg-associated immunosuppression during the neoplastic transformation in spirocercosis and one potential mechanism is a systemic response driven by circulating cytokines. It is, therefore imperative to investigate the cytokine milieu in canine spirocercosis and to determine if it is Th1-related, Th2-related, immunosuppressive or pro-inflammatory.

Since cytokines work in networks, several canine plasma cytokines including GM-CSF, IL-2, IL-4, IL-6, IL8 , IL-10, IL-18 and MCP-1 should be measured. Of these cytokines IL-2, IL-6, IL- 8 and IL-18 are pro-inflammatory and IL-4 and IL-10 are immunoregulatory. The proinflammatory cytokines such as IL-2 enhance the cytolytic activity of T lymphocytes and NK cells (Antony and Dudek, 2010). It is a Th1-related-interleukin and has major anti-tumour activity. IL-2 works synergistically with IL-18 (Srivastava et al., 2010). IL-6 is another pro-inflammatory cytokine that is classified as a major pro-tumourogenic cytokine. It serves as a growth and survival factor that stimulates angiogenesis, tumour progression and metastasis, and it is reported to maintain tumour-promoting inflammation (Grivennikov and Karin, 2011). Cancer cells, including tumour-associated fibroblasts, are also capable of IL- 6 production and can significantly contribute to the serum concentration of this cytokine (Grivennikov and Karin, 2011). Elevated IL-6 was suggested as a useful biomarker for poor prognosis in dogs with cancer (Itoh et al., 2009), yet it was also successfully used as therapy in dogs with transmissible venereal tumours demonstrating anti-tumour activity (Chou et al., 2009).

Interleukin-8 is another pro-inflammatory cytokine that is expected to be elevated in malignancy. It is regarded as a significant regulatory factor within the tumour microenvironment and is produced by various inflammatory cells, but also by tumour cells (Waugh and Wilson, 2008). Secretion of IL-8 from cancer cells can enhance their proliferation and survival, promote angiogenesis and induce chemotactic infiltration of neutrophils into the tumour site. Elevated serum IL-8 was correlated with tumour progression in humans with oesophageal squamous cell carcinoma (Diakowska et al., 2006; Krzystek-Korpacka et al., 2008). It was also detected in Barret's oesophagus (Fitzgerald et al., 2002), a human condition that involves oesophageal inflammation due to influx, epithelial dysplasia and metaplasia and eventually neoplastic transformation. The expression of IL-8 increases as the diseases progresses to cancer (Oh et al., 2007).

IL-18, like IL-2, enhances cytolytic activity of natural killer (NK) cells and cytotoxic T lymphocytes. IL-18 is a critical molecule in the activation of the Th1 immune response (Park et al., 2007). Like many cytokines, IL-18 has dual effects in cancer progression; namely enhancing anti-tumour immunity and promoting tumour progression (Park et al., 2007). Higher expression or secretion of IL18 is detected in various cancer cells in comparison with normal controls and IL-18 is able to induce tumour angiogenesis, migration/metastasis, proliferation and immune evasion (Park et al., 2007). IL-18 stimulates production of vascular endothelial growth factor (VEGF) mRNA and the final protein product leading to angiogenesis (Park et al., 2007). VEGF is highly expressed in spirocercosis-induced neoplasia (Dvir and Clift, 2010). Elevated serum IL-18 was found in humans with oesophageal squamous cell carcinoma and correlated with tumour progression (Diakowska et al., 2006; Krzystek-Korpacka et al., 2008).

IL-4 is a typical Th2-related cytokine and is therefore, not "expected" to have a major anti-tumour effect. In fact, many Th2-related cytokines are regarded as immunosuppressive and "tumour promoting". This approach has, however, been proven to be over-simplistic, because IL-4 can also contribute to tumour rejection by boosting eosinophil function and increased antibody reaction (Dranoff, 2004). Therefore, it is not surprising that therapy with IL-4 shows an anti-tumour effect (Dranoff, 2004). IL10 is the typical immunoregulatory cytokine, being a Tregand Th2-related cytokine. It is widely believed that Treg 
function in cancer is mainly to suppress protective anticancer inflammatory responses (Beyer and Schultze, 2006). The role of Treg and the associated IL-10 is paradoxical, since IL-10 and Treg also reduce inflammation associated with infectious diseases ("hygiene theory"). This ability to reduce inflammation consequently inhibits or suppresses cancer (Erdman and Poutahidis, 2010).

Granulocyte-macrophages colony-stimulated factor (GM-CSF) is important in the process of protection from infection-induced cancer. GM-CSF/INF- $\gamma$ double-knockout mice developed diverse haematological and solid neoplasms after various chronic infections and inflammations (Dranoff, 2004). GM-CSF is also used as an adjuvant in anti-cancer therapy in a few types of cancer in clinical trials. However, as many other cytokines, GM-CSF has a dual effect in cancer immunity and it also promotes invasion and dissemination of breast carcinoma in a transgenic mouse model.

Monocyte chemotactic protein-1 (MCP-1) is a chemokine that was originally termed 'tumour derived chemotactic protein'. It is secreted by several tumour cell lines and it is a potent chemotactic protein for monocytes, neutrophils, memory T cells and NK cells as well as stimulant for emigration of myeloid cells from the bone marrow (Perry et al., 2010). The early (non-neoplastic) spirocercosis nodules consist of massive pockets of MAC387+ myeloid cells (Dvir et al., 2011). It is likely that this response is a normal innate response to the pathogen. Expression of MCP-1 is a biomarker for poor outcomes in breast carcinoma and ovarian cancer in humans and it has been associated with a poor prognosis in dogs diagnosed with lymphoma (Perry et al., 2010). Therefore, it is of interest to investigate its level in the different stages of spirocercosis.

In summary, it is of great interest to investigate the cytokine milieu and especially this set of cytokines in spirocercosis. We hypothesise that the cytokines expressed in spirocercosis (an infectious disease that progress to aggressive cancer with marked inflammation) will serve as biomarkers for neoplastic transformation and provide insights into the pathogenesis of this process.

\section{Material and methods}

\subsection{Study population}

The study population comprised of client-owned dogs admitted to the Onderstepoort Veterinary Academic Hospital, at the Faculty of Veterinary Science, University of Pretoria between 2008 and 2011. The study was approved by the faculty's animal use and care committee. The dogs were divided into 3 groups, non-neoplastic, neoplastic and healthy controls.

An initial diagnosis of spirocercosis was made by one of the following criteria: a faecal float that was positive for $S$. lupi worm eggs or radiological signs consistent with S. lupi infection, namely caudodorsal mediastinal mass together with spondylitis of the caudal thoracic vertebrae or undulation of the lateral border of the descending aorta (2 pathognomonic radiological signs associated with spirocercosis).
Classifying the mass as non-neoplastic was done by one of the following criteria:

- The masses had the typical smooth appearance of nonneoplastic nodules on endoscopy and responded to treatment monitored by follow-up endoscopy at 6 weeks and again at 12 weeks, if a poor initial response was shown at 6 weeks.

- Histopathological evaluation of the entire oesophageal nodule showed no evidence of neoplastic transformation. The sample was obtained by either surgical excision of the mass or necropsy.

Classifying the mass as neoplastic was performed by one of the following criteria:

- Histopathological diagnosis of neoplastic transformation by endoscopy-guided biopsy or post-necropsy.

- Metastatic lesions in the lungs, together with radiological signs associated with S. lupi and no other diagnosed neoplasm.

Cases that could not be classified as non-neoplastic or neoplastic were excluded $(n=3)$.

The control group was composed of dogs that were presented for ovariohistorectomy, castration or blood donation. They were healthy by definition, had a full clinical history and had normal clinical examination and haematology. All dogs were negative for spirocercosis on faecal floatation and most of the dogs had thoracic radiographs and all thoracic radiographs were negative for S. lupi. They were age- and gender-matched with the other study groups.

\subsection{Patient sampling}

Blood samples were collected at admission by jugular veinpuncture with a $21 \mathrm{~g}$ needle and a $5 \mathrm{ml}$ potassium EDTA vacutainer syringe. The samples were then immediately centrifuged, separated, aliquoted and frozen at $-80^{\circ} \mathrm{C}$. The samples were batched and analysed together.

\subsection{Analyses}

Plasma cytokine concentrations were assessed at the department of Small Animal Clinical Sciences, University of Copenhagen, Denmark by a canine-specific multiplex assay (CCYTO-90K, Millipore, Billerica, MA) including internal quality control material with an automated analyzer (Luminex 200, Luminex Corporation, Austin, TX) for interleukin-2 (IL-2), IL-4, IL-6, IL-8, IL-10, IL-18, MCP-1 and GM-CSF (Kjelgaard-Hansen et al., 2011).

\subsection{Data analysis}

The median of each cytokine plasma concentration of each group was calculated and compared between groups using Kruskal-Wallis test, followed by Dunn's test for differences between specific pairs of groups. The level of significance was set at $p \leq 0.05$. 


\section{Results}

One hundred and three dogs were enrolled in the study and were divided into 3 groups, non-neoplastic $(n=49)$, neoplastic $(n=29)$ and healthy control $(n=25)$. Seventy six out of the 78 dogs with spirocercosis had oesophageal endoscopy performed and the typical oesophageal $S$. lupi nodule(s) were identified. The 49 non-neoplastic cases had the typical smooth appearance and responded to doramectin treatment. Twenty seven neoplastic cases had the characteristic cauliflower-like appearance on endoscopy and/or necropsy with area of necrosis and ulceration and were diagnosed by histopathology as sarcoma. The remaining 2 cases were neoplastic cases that were diagnosed based on the pathognomonic radiological signs and metastases in the lungs. The neoplastic nature of the lesion was later confirmed by necropsy in 1 of the 2 cases.

Interleukin 2, IL-4, IL-6, IL-10, MCP-1 and GM-CSF concentrations were not significantly different between the three groups. Only IL- 8 and IL-18 showed significant differences in their plasma concentrations among the three groups. The highest median IL-8 concentration was in the neoplastic group $[634 \mathrm{pg} / \mathrm{ml}$, interquartile range (IR), $309-1230]$, followed by the non-neoplastic $(429 \mathrm{pg} / \mathrm{ml}$, IR 161-1277) and the control groups $(150 \mathrm{pg} / \mathrm{ml}$, IR 33-446). Post-test analysis revealed a significance difference between the two $S$. lupi groups and the control group (neoplastic vs. control, $p=0.002$ and non-neoplastic vs. control, $p=0.003$ ). The highest IL-18 concentration was in the non-neoplastic group ( $53 \mathrm{pg} / \mathrm{ml}$, IR 25-156), followed by the control group (46 pg/ml, IR 24-264) and finally the lowest concentration was found in the neoplastic group (33 pg/ml, IR 1.6-79). Post-test analysis revealed that IL-18 concentrations were significantly higher in the nonneoplastic group than in the neoplastic group $(p=0.05)$. There was a trend toward a low IL-2 in the neoplastic group compared to the non-neoplastic and the control groups (Table 1).

\section{Discussion}

This study investigated key plasma cytokine concentrations in canine spirocercosis. Although this disease is associated with a severe systemic and local inflammatory response (Dvir et al., 2011; Mukorera et al., 2011), the plasma cytokine milieu has never been investigated. The most significant finding in this study is the increased concentration of IL-8 in the spirocercosis group and especially the neoplastic group. However, despite a marked difference between the median IL-8 plasma concentration between the neoplastic and the non-neoplastic groups $(634 \mathrm{pg} / \mathrm{ml}$ and $429 \mathrm{pg} / \mathrm{ml}$, respectively), the difference was not significant, most probably due to the wide range within each group and the substantial overlap between the ranges [interquartile range (IR), 309-1230, and 161-1277, respectively]. IL-8 is a chemoattractant for neutrophils, which in turn can also produce IL-8 (Wiinberg et al., 2005). The high concentrations of IL-8 seen in this study is, therefore, in agreement with previous studies that showed an intense neutrophilic inflammatory reaction within the nodule (Dvir et al., 2010, 2011), neutrophilia (Dvir et al.,
2008) and elevated serum CRP (Mukorera et al., 2011). Interestingly, a recent publication described an increased activation of canine neutrophils with increased production of IL-8 as a response to Wolbachia surface protein (Bazzocchi et al., 2003). Wolbachia is an endosymbiont of Dirofilaria immitis and Dirofilaria repens and the study speculates that these findings can explain some of the inflammatory features of dirofilariosis in the dog. It is possible that $S$. lupi also harbours bacteria that are responsible for the inflammatory response, which may explain why the inflammatory features are different from what is expected in helminth infection (namely elevated Th2- and Tregassociated cytokines). Interestingly, Wolbachia was found to be associated with tumour development in a filariae called Onchocerca volvulus and treating the bacteria with doxycycline reduced the incidence of tumour development in this filariae (Brattig et al., 2010), emphasizing the oncogenic potential of those endobacteria. The association between up-regulated IL- 8 and bacterial infection-induced cancer is well demonstrated in Helicobacter pylori $(H$. pylori)-induced chronic gastritis in humans, where it is proposed to play a role in the neoplastic transformation to adenocarcinoma (Wiinberg et al., 2005). IL-8 was also highly expressed in dogs infected with Helicobacter spp (Wiinberg et al., 2005), correlating with the intensity of the infection-associated neutrophilic infiltrate (Wiinberg et al., 2005). However, $H$. pylori infection is more associated with lymphocytic hyperplasia, where IL-8 is highly expressed in correlation with the lymphocytic infiltrate (Straubinger et al., 2003), which is the second most common inflammatory infiltrate in spirocercosis. IL-8 was uniformly over-expressed in dogs with osteosarcoma and its expression was associated with poor outcome in paediatric osteosarcoma patients (Paoloni et al., 2009). This is of specific interest, considering the fact that osteosarcoma is the most common spirocercosis-associated tumour (Dvir et al., 2010).

Another condition, where the cytokine milieu is quite similar to this study, namely increased IL-8 and no change in IL-4 and IL-10, is gastro-oesophageal reflux disease and especially Barrett's oesophagus in humans (Jenkins et al., 2007; Rieder et al., 2010). In Barrett's oesophagus there is also further increases in IL-8 as the disease progresses to adenocarcinoma and it is found to be upregulated by NF-кb (Jenkins et al., 2007). The possibility that spirocercosis-induced cancer can serve as a model for Barret's oesophagus-induced cancer warrants further investigation, as this is an emerging cause of oesophageal cancer in the western world. In reflux oesophageal diseases in humans, IL-8 is also secreted by fibroblasts, epithelial and endothelial cells and because it is a potent chemoattractant of neutrophils that further secrete IL-8, it creates a spiral of inflammation and damage leading to further injury (Jenkins et al., 2007). This cascade of events can also happen in spirocercosis in the dog, where fibroblasts are abundant (Dvir et al., 2010). The question remains, whether the innate response, and its potentially associated increased IL-8 expression, has a role in the neoplastic transformation.

IL-18, a typical pro-inflammatory cytokine that induces IFN- $\gamma$ production and stimulates Th1 immune responses, was significantly lower in the neoplastic group compared 
Table 1

The different cytokines plasma concentrations $(\mathrm{pg} / \mathrm{ml})$ in the different groups.

\begin{tabular}{|c|c|c|c|c|c|c|c|c|}
\hline \multirow[t]{2}{*}{ Cytokine } & \multirow[t]{2}{*}{ Detection limit (DL) } & \multicolumn{2}{|c|}{ Neoplastic } & \multicolumn{2}{|c|}{ Non-neoplastic } & \multicolumn{2}{|l|}{ Control } & \multirow[b]{2}{*}{$\mathrm{P}$} \\
\hline & & Median & Interquartile range & Median & Interquartile range & Median & Interquartile range & \\
\hline IL-2 & 6.4 & 18 & $7-72$ & 38 & $17-137$ & 28 & $9-233$ & 0.18 \\
\hline IL-4 & 28.8 & $<\mathrm{DL}$ & $<\mathrm{DL}$ to $<\mathrm{DL}$ & $<\mathrm{DL}$ & $<$ DL to $<\mathrm{DL}$ & $<\mathrm{DL}$ & $<\mathrm{DL}$ to $<\mathrm{DL}$ & 0.65 \\
\hline IL-6 & 12.1 & $<\mathrm{DL}$ & $<$ DL to $<$ DL & $<\mathrm{DL}$ & $<$ DL to $<\mathrm{DL}$ & $<\mathrm{DL}$ & $<$ DL to $<$ DL & 0.99 \\
\hline IL-8 & 20.3 & 634 & 309-945 & 429 & $161-1277$ & 150 & $34-446$ & $<0.01$ \\
\hline IL-10 & 1.6 & $<\mathrm{DL}$ & $<$ DL to 7 & $<\mathrm{DL}$ & $<$ DL to 4 & $<\mathrm{DL}$ & $<\mathrm{DL}$ to $<\mathrm{DL}$ & 0.26 \\
\hline IL-18 & 4.6 & 33 & $1.6-79$ & 53 & $25-156$ & 46 & $24-264$ & 0.05 \\
\hline MCP-1 & 8.6 & 209 & $100-334$ & 163 & $116-377$ & 142 & $101-276$ & 0.43 \\
\hline GM-CSF & 14.4 & 26 & $<$ DL to 93 & 42 & $18-145$ & 35 & $17-172$ & 0.62 \\
\hline
\end{tabular}

to the non-neoplastic group. In the current study it is not clear if the reduced IL-18 is related to spirocercosis infection, because the non-neoplastic group was not different from the control and in the neoplastic cases the worm is often not present any more (Dvir et al., 2010). However, the possibility that the low IL-18 is related to prolonged $S$. lupi infection, evasion of the host response and the neoplastic transformation cannot be excluded. Decreased IL-18 is unusual in cancer patients, but decreased Th1 cytokines such as IL-18 is commonly observed in chronic helminth infections across species. There are, however, a few reports of increased IL-18 in a number of nematodes infections such as Trichuris muris (Grencis, 2001) and Trichinella spiralis (Helmby and Grencis, 2002) and trematodes infections such as S. mansoni (Hogg et al., 2003) and Schistosoma japonicum (He et al., 2002). One mechanisms in which IL-18 plays a role in down-regulating the normal anti-helminth response is by inhibiting mast cells function (Helmby et al., 2001), but there is also contrasting evidence showing that IL-18 treatment is associated with prominent mastocytosis and increased expulsion of Strongyloides venezuelenzis in mice (Sasaki et al., 2005). Clinical studies, such as ours cannot establish cause and effect relationships, but indicate that the role of IL-18 in canine spirocercosis warrants further investigation.

Chronic helminth infections are often associated with increased Th2-associated cytokines, such as IL-4 and IL-10, a pattern that was also described in dogs with $D$. immitis (Morchon et al., 2007). In Toxocara canis infection in the dog the production of the Th2- and Treg-associated cytokine, IL10 , is increased while the production of the Th1-associated cytokines, IL-18 and INF- $\gamma$ are decreased (Torina et al., 2005). Such a response is often described as "immunoregulatory" or "immunosuppressive" and because it also promotes or is associated with cancer formation, our central hypothesis was that these cytokines would be increased in the $S$. lupi cases, especially the ones with the neoplastic transformation. However, this was not the case and IL-4 and IL-10 showed very low concentrations in the $S$. lupi groups as well as the controls. We have considered the possibility that these results might be kit dependent, however, the respective kits' detection limits $(1.6 \mathrm{pg} / \mathrm{ml})$ is much lower than the IL-10 concentrations that was reported in dogs in a study that was performed in our laboratory (Kjelgaard-Hansen et al., 2007).

Our study aim was also to assess if any of the investigated cytokines may serve as a biomarker for neoplastic transformation. In that respect elevated IL-8 might indicate neoplastic transformation, while high IL-18 indicated non-neoplastic transformation.

\section{Acknowledgements}

This study was funded by the European College of Veterinary Internal Medicine-Companion Animal (ECVIM-CA) Clinical Research Fund by The Department of Companion Animal Clinical Studies, Faculty of Veterinary Science, University of Pretoria and the Duncan Campbell Memorial Fund of the South African Veterinary Foundation (SAVF). The authors would like to thank Srs. Carla van der Merwe and Marizelle DeClercq for their help in the administration and organizations of the patients, the samples and the required procedures.

\section{References}

Antony, G.K., Dudek, A.Z., 2010. Interleukin 2 in cancer therapy. Curr. Med. Chem. 17, 3297-3302.

Bailey, W.S., 1972. Spirocerca lupi: a continuing inquiry. J. Parasitol. 58, $3-22$.

Bazzocchi, C., Genchi, C., Paltrinieri, S., Lecchi, C., Mortarino, M., Bandi, C., 2003. Immunological role of the endosymbionts of Dirofilaria immitis: the Wolbachia surface protein activates canine neutrophils with production of IL-8. Vet. Parasitol. 117, 73-83.

Betts, G., Twohig, J., Van den Broek, M., Sierro, S., Godkin, A., Gallimore, A., 2007. The impact of regulatory T cells on carcinogen-induced sarcogenesis. Br. J. Cancer 96, 1849-1854.

Beyer, M., Schultze, J.L., 2006. Regulatory T cells in cancer. Blood 108, 804-811.

Brattig, N.W., Hoerauf, A., Fischer, P.U., Liebau, E., Bandi, C., Debrah, A., Buttner, M., Buttner, D.W., 2010. Immunohistological studies on neoplasms of female and male Onchocerca volvulus: filarial origin and absence of Wolbachia from tumor cells. Parasitology 137, 841-854.

Carreras, J., Lopez-Guillermo, A., Fox, B.C., Colomo, L., Martinez, A., Roncador, G., Montserrat, E., Campo, E., Banham, A.H., 2006. High numbers of tumor-infiltrating FOXP3-positive regulatory T cells are associated with improved overall survival in follicular lymphoma. Blood 108, 2957-2964.

Chou, P.C., Chuang, T.F., Jan, T.R., Gion, H.C., Huang, Y.C., Lei, H.J., Chen, W.Y., Chu, R.M., 2009. Effects of immunotherapy of IL-6 and IL-15 plasmids on transmissible venereal tumor in beagles. Vet. Immunol. Immunopathol. 130, 25-34.

Diakowska, D., Markocka-Maczka, K., Grabowski, K., Lewandowski, A., 2006. Serum interleukin-12 and interleukin-18 levels in patients with oesophageal squamous cell carcinoma. Exp. Oncol. 28, 319-322.

Dranoff, G., 2004. Cytokines in cancer pathogenesis and cancer therapy. Nat. Rev. Cancer 4, 11-22.

Dvir, E., Clift, S.J., 2010. Evaluation of selected growth factor expression in canine spirocercosis (Spirocerca lupi)-associated non-neoplastic nodules and sarcomas. Vet. Parasitol. 174, 257-266. 
Dvir, E., Clift, S.J., Williams, M.C., 2010. Proposed histological progression of the Spirocerca lupi-induced oesophageal lesion in dogs. Vet. Parasitol. 168, 71-77.

Dvir, E., Kirberger, R.M., Malleczek, D., 2001. Radiographic and computed tomographic changes and clinical presentation of spirocercosis in the dog. Vet. Radiol. Ultrasound 42, 119-129.

Dvir, E., Kirberger, R.M., Mukorera, V., van der Merwe, L.L., Clift, S.J., 2008. Clinical differentiation between dogs with benign and malignant spirocercosis. Vet. Parasitol. 155, 80-88.

Dvir, E., Schoeman, J.P., Clift, S.J., McNeilly, T.N., Mellanby, R.J., 2011. Immunohistochemical characterization of lymphocyte and myeloid cell infiltrates in spirocercosis-induced esophageal nodules. Parasite Immunol. 33, 545-553.

Erdman, S.E., Poutahidis, T., 2010. Roles for inflammation and regulatory T cells in colon cancer. Toxicol. Pathol. 38, 76-87.

Fitzgerald, R.C., Abdalla, S., Onwuegbusi, B.A., Sirieix, P., Saeed, I.T., Burnham, W.R., Farthing, M.J., 2002. Inflammatory gradient in Barrett's oesophagus: implications for disease complications. Gut 51, 316-322.

Grencis, R.K., 2001. Cytokine regulation of resistance and susceptibility to intestinal nematode infection - from host to parasite. Vet. Parasitol. $100,45-50$.

Grivennikov, S.I., Karin, M., 2011. Inflammatory cytokines in cancer: tumour necrosis factor and interleukin 6 take the stage. Ann. Rheum. Dis. 70 (Suppl. 1), i104-i108.

He, Y.X., Chen, L., Ramaswamy, K., 2002. Schistosoma mansoni, S. haematobium, and S. japonicum: early events associated with penetration and migration of schistosomula through human skin. Exp. Parasitol. 102, 99-108.

Helmby, H., Grencis, R.K., 2002. IL-18 regulates intestinal mastocytosis and Th2 cytokine production independently of IFN-gamma during Trichinella spiralis infection. J. Immunol. 169, 2553-2560.

Helmby, H., Takeda, K., Akira, S., Grencis, R.K., 2001. Interleukin (IL)-18 promotes the development of chronic gastrointestinal helminth infection by downregulating IL-13. J. Exp. Med. 194, 355-364.

Herrera, L.A., Benitez-Bribiesca, L., Mohar, A., Ostrosky-Wegman, P., 2005. Role of infectious diseases in human carcinogenesis. Environ. Mol Mutagen. 45, 284-303.

Hogg, K.G., Kumkate, S., Anderson, S., Mountford, A.P., 2003. Interleukin12 p40 secretion by cutaneous CD11c+ and F4/80+ cells is a major feature of the innate immune response in mice that develop Th1mediated protective immunity to Schistosoma mansoni. Infect. Immun. 71, 3563-3571.

Imai, H., Saio, M., Nonaka, K., Suwa, T., Umemura, N., Ouyang, G.F., Nakagawa, J., Tomita, H., Osada, S., Sugiyama, Y., Adachi, Y., Takami, T., 2007. Depletion of CD4+CD25+ regulatory $T$ cells enhances interleukin-2-induced antitumor immunity in a mouse model of colon adenocarcinoma. Cancer Sci. 98, 416-423.

Itoh, H., Horiuchi, Y., Nagasaki, T., Sakonju, I., Kakuta, T., Fukushima, U., Uchide, T., Yamashita, M., Kuwabara, M., Yusa, S., Takase, K., 2009. Evaluation of immunological status in tumor-bearing dogs. Vet Immunol. Immunopathol. 132, 85-90.

Jenkins, G.J., Mikhail, J., Alhamdani, A., Brown, T.H., Caplin, S., Manson, J.M., Bowden, R., Toffazal, N., Griffiths, A.P., Parry, J.M., Baxter, J.N. 2007. Immunohistochemical study of nuclear factor-kappaB activity and interleukin- 8 abundance in oesophageal adenocarcinoma; a useful strategy for monitoring these biomarkers. J. Clin. Pathol. 60, 1232-1237.

Kjelgaard-Hansen, M., Goggs, R., Wiinberg, B., Chan, D.L., 2011. Use of serum concentrations of interleukin-18 and monocyte chemoattractant protein- 1 as prognostic indicators in primary immune-mediated hemolytic anemia in dogs. J. Vet. Intern. Med. 25, 76-82.

Kjelgaard-Hansen, M., Luntang-Jensen, M., Willesen, J., Jensen, A.L., 2007. Measurement of serum interleukin-10 in the dog. Vet. J. 173, 361-365.

Kok, D.J., Williams, E.J., Schenker, R., Archer, N.J., Horak, I.G., 2010. The use of milbemycin oxime in a prophylactic anthelmintic programme to protect puppies, raised in an endemic area, against infection with Spirocerca lupi. Vet. Parasitol. 174, 277-284.

Krzystek-Korpacka, M., Matusiewicz, M., Diakowska, D., Grabowski, K., Blachut, K., Konieczny, D., Kustrzeba-Wojcicka, I., Terlecki, G., Banas, T., 2008. Elevation of circulating interleukin-8 is related to lymph node and distant metastases in esophageal squamous cell carcinomas - implication for clinical evaluation of cancer patient. Cytokine 41, 232-239.

Meeusen, E.N., 1999. Immunology of helminth infections, with special reference to immunopathology. Vet. Parasitol. 84, 259-273.

Morchon, R., Lopez-Belmonte, J., Bazzocchi, C., Grandi, G., Kramer, L., Simon, F., 2007. Dogs with patent Dirofilaria immitis infection have higher expression of circulating IL-4 IL-10 and iNOS mRNA than those with occult infection. Vet. Immunol. Immunopathol. 115, $184-188$.

Mukorera, V., Dvir, E., van der Merwe, L.L., Goddard, A., 2011. Serum C-reactive protein concentration in benign and malignant canine spirocercosis. J. Vet. Intern. Med. 25, 963-966.

Oh, D.S., DeMeester, S.R., Vallbohmer, D., Mori, R., Kuramochi, H., Hagen, J.A., Lipham, J., Danenberg, K.D., Danenberg, P.V., Chandrasoma, P., DeMeester, T.R., 2007. Reduction of interleukin 8 gene expression in reflux esophagitis and Barrett's esophagus with antireflux surgery. Arch. Surg. 142, 554-559, discussion 559-560.

Paoloni, M., Davis, S., Lana, S., Withrow, S., Sangiorgi, L., Picci, P., Hewitt, S., Triche, T., Meltzer, P., Khanna, C., 2009. Canine tumor cross-species genomics uncovers targets linked to osteosarcoma progression. BMC Genomics 10, 625 .

Park, S., Cheon, S., Cho, D., 2007. The dual effects of interleukin-18 in tumor progression. Cell Mol. Immunol. 4, 329-335.

Perry, J.A., Thamm, D.H., Eickhoff, J., Avery, A.C., Dow, S.W., 2010. Increased monocyte chemotactic protein-1 concentration and monocyte count independently associate with a poor prognosis in dogs with lymphoma. Vet. Comp. Oncol. 9, 55-64.

Rieder, F., Biancani, P., Harnett, K., Yerian, L., Falk, G.W., 2010. Inflammatory mediators in gastroesophageal reflux disease: impact on esophageal motility, fibrosis, and carcinogenesis. Am. J. Physiol. Gastrointest. Liver Physiol. 298, G571-G581.

Sasaki, Y., Yoshimoto, T., Maruyama, H., Tegoshi, T., Ohta, N., Arizono, N., Nakanishi, K., 2005. IL-18 with IL-2 protects against Strongyloides venezuelensis infection by activating mucosal mast cell-dependent type 2 innate immunity. J. Exp. Med. 202, 607-616.

Srivastava, S., Salim, N., Robertson, M.J., 2010. Interleukin-18: biology and role in the immunotherapy of cancer. Curr. Med. Chem. 17, 3353-3357.

Straubinger, R.K., Greiter, A., McDonough, S.P., Gerold, A., Scanziani, E., Soldati, S., Dailidiene, D., Dailide, G., Berg, D.E., Simpson, K.W., 2003. Quantitative evaluation of inflammatory and immune responses in the early stages of chronic Helicobacter pylori infection. Infect. Immun. 71, 2693-2703.

Torina, A., Caracappa, S., Barera, A., Dieli, F., Sireci, G., Genchi, C., Deplazes, P., Salerno, A., 2005. Toxocara canis infection induces antigen-specific IL-10 and IFNgamma production in pregnant dogs and their puppies. Vet. Immunol. Immunopathol. 108, 247-251.

Unitt, E., Rushbrook, S.M., Marshall, A., Davies, S., Gibbs, P., Morris, L.S., Coleman, N., Alexander, G.J., 2005. Compromised lymphocytes infiltrate hepatocellular carcinoma: the role of T-regulatory cells. Hepatology 41, 722-730.

Vennervald, B.J., Polman, K., 2009. Helminths and malignancy. Parasite Immunol. 31, 686-696.

Waugh, D.J., Wilson, C., 2008. The interleukin-8 pathway in cancer. Clin. Cancer Res. 14, 6735-6741.

Wiinberg, B., Spohr, A., Dietz, H.H., Egelund, T., Greiter-Wilke, A., McDonough, S.P., Olsen, J., Priestnall, S., Chang, Y.F., Simpson, K.W., 2005. Quantitative analysis of inflammatory and immune responses in dogs with gastritis and their relationship to Helicobacter spp. infection. J. Vet. Intern. Med. 19, 4-14.

Xue, L., Lu, H.Q., He, J., Zhao, X.W., Zhong, L., Zhang, Z.Z., Xu, Z.F., 2009. Expression of FOXP3 in esophageal squamous cell carcinoma relating to the clinical data. Dis. Esophagus 23, 340-346.

Yoshida, A., Maruyama, H., Kumagai, T., Amano, T., Kobayashi, F., Wang, J., Kuribayashi, K., Ohta, N., 2002. Enhanced UVfemale1 tumor growth in CBF1 mice infected with Schistosoma mansoni due to modulation of Th1-like responses. Parasitol. Int. 51, 177-186. 